\title{
PERTUMBUHAN DAN MUTU FISIK BIBIT MERAWAN (Hopea odorata Roxb.) ASAL SISTEM KOFFCO DI POLIBAG DAN POTRAY
}

(Growth and Physical Quality of Merawan (Hopea odorata Roxb.) Seedling from KOFFCO System on Polybag and Potrays)

Oleh/By:

Ahmad Junaedi

Balai Penelitian Teknologi Serat Tanaman Hutan Kuok

\begin{abstract}
The objective of this research is to find out the growth and physical quality of Hopea odorata Roxb. seedlings from KOFFCO system grown on polybag and potrays. Growth observation and physical quality assessment were done to Hopea odorata Roxb. seedlings at six months old placed on polybag (500 $\mathrm{cm}^{3}$ of volume) and potrays (cubical potray: $400 \mathrm{~cm}^{3}$ of volume and cylindrical potray: $350 \mathrm{~cm}^{3}$ of volume). Observation and assessment were done to three seedling sample of each container item which selected through simple randomized sampling method. The result showed that shoot diameter of seedlings on polybag (seedling A) were significantly $(p<0.05)$ better than seedling on cubical and cylindrical potrays (seedling $B$ and C). Referring to biomass growth, seedling A 29\% faster than seedling $B$ and $C$. On the other hand, seedling $A$ physical quality was better than $B$ and $C$. At six months old, seedling $A$ was ready to be planted with height of $21.59 \mathrm{~cm}$, shoot/root ratio was 2.2, and seedling quality index was 0.46 .
\end{abstract}

Key Words : Seedling, height, shoot/root ratio and seedling quality index.

\begin{abstract}
ABSTRAK
Penelitian ini bertujuan untuk mengetahui pertumbuhan dan mutu fisik bibit (Hopea odorata Roxb.) asal sistem KOFFCO pada polibag dan potray. Penelitian dilakukan melalui pengamatan parameter pertumbuhan dan penilaian mutu fisik bibit merawan asal KOFFCO sistem berumur enam bulan setelah sapih (6 BSS) yang ditumbuhkan pada polibag (volume $500 \mathrm{~cm}^{3}$ ) dan potray (potray kotak volume $400 \mathrm{~cm}^{3}$ dan potray bulat volume $350 \mathrm{~cm}^{3}$ ). Pengamatan dan penilaian tersebut dilakukan terhadap 10 sampel bibit pada tiap macam wadah yang dipilih secara sampling menggunakan teknik simple random sampling. Hasil penelitian menunjukkan bahwa diameter tunas bibit di polibag (A) secara nyata $(\mathrm{p}<0,05)$ lebih baik dibandingkan bibit di potray kotak $(\mathrm{B})$ dan bulat $(\mathrm{C})$. Berdasarkan pertumbuhan biomassanya (berat kering total), laju pertumbuhan A lebih cepat 0,29 kali dibandingkan B dan C. Sementara itu nilai kualitas fisik bibit menunjukkan bahwa bibit A lebih baik dibandingkan bibit B dan C, walaupun secara statistik tidak berbeda nyata $(\mathrm{p}<0,05)$. Pada umur 6 BSS, bibit A sudah siap tanam karena mempunyai tinggi lebih dari $20 \mathrm{~cm}(21,59 \mathrm{~cm})$, rasio pucuk akar ada pada kisaran 2-5 $(2,1)$ dan indeks mutu bibit lebih dari $0,09(0,46)$.
\end{abstract}

Kata Kunci : Bibit, tinggi, rasio pucuk akar dan indeks mutu bibit. 


\section{PENDAHULUAN}

Merawan (Hopea odorata Roxb.) merupakan salah satu jenis dari suku Dipterocarpaceae, memiliki prospek yang baik untuk dikembangkan di hutan tanaman. Hal ini antara lain diindikasikan oleh pertumbuhan yang cepat dan daya hidup yang tinggi. Diameter pada umur 25 tahun mencapai 53 $\mathrm{cm}$ dan survival rate-nya hampir 100\% (Soerinegara dan Lemmens, 1994). Weinland (1998) menyatakan bahwa dari 16 jenis kriteria yang membahas kelayakan pembangunan hutan tanaman Dipterocarpaceae, salah satu jenis yang direkomendasikan dikembangkan adalah merawan.

Upaya pembangunan hutan tanaman jenis merawan (Hopea odorata Roxb.) perlu didukung oleh ketersediaan bibit dalam jumlah dan waktu ketersediaan yang memadai. Keperluan tersebut dimungkinkan akan dicapai melalui aplikasi teknik perbanyakan massal sistem KOFFCO. Aplikasi teknik ini pada jenis merawan telah menunjukkan tingkat keberhasilan persentase berakar yang tinggi yaitu mencapai 83,5\%- 96,2\% (Sakai dan Subiakto, 2007; Hidayat et al., 2008). Untuk keperluan operasional, fakta keberhasilan sistem KOFFCO pada perbanyakan bibit merawan perlu didukung oleh manajemen persemaian yang baik. Salah satu bagian dari manajemen persemaian adalah pemilihan wadah bibit yang akan digunakan.

Pada tingkat lapangan ada tiga wadah bibit yang biasa digunakan di persemaian, yaitu polibag, potray kotak dan potray bulat. Perbedaan wadah yang digunakan akan mempengaruhi efisiensi penggunaan media dan waktu pemeliharaan. Pada wadah yang lebih besar dengan volume media yang lebih banyak dimungkinkan akan menyebabkan bibit lebih cepat tumbuh dan siap ditanam sehingga waktu pemeliharaan bibit di persemaian bisa lebih singkat. Namun demikian, selain media yang dibutuhkan akan lebih banyak, tenaga dan waktu yang diperlukan pun akan lebih banyak. Sementara itu, media yang digunakan pada wadah yang lebih kecil yaitu potray akan lebih sedikit (efisien). Akan tetapi, dengan volume media yang lebih kecil, dimungkinkan pertumbuhan bibit akan cenderung lebih lambat sehingga bibit pun akan lebih lambat siap tanam. Akibatnya, pemeliharaan bibit di persemaian akan lebih lama. Untuk menjawab kemungkinan-kemungkinan tersebut maka perlu dilakukan kajian terhadap pertumbuhan dan mutu fisik bibit merawan asal sistem KOFFCO pada wadah bibit polibag dan potray.

Tujuan penelitian ini adalah untuk mengetahui pertumbuhan dan mutu fisik bibit merawan asal sistem KOFFCO pada wadah bibit polibag dan potray. Data dan informasi pertumbuhan dan mutu fisik bibit tersebut diperlukan sebagai bagian yang diperhitungkan dalam pemilihan wadah bibit yang paling sesuai. 


\section{METODE PENELITIAN}

\section{A. Waktu dan Tempat}

Penelitian dilaksanakan pada bulan Juni - Agustus 2007 di persemaian Balai Penelitian Hutan Penghasil Serat (BPHPS) Kuok, Riau. Lokasi berada pada ketinggian $52 \mathrm{~m}$ dpl, dengan tipe iklim A menurut klasifikasi iklim Schmidth \& Ferguson (1951).

\section{B. Bahan dan Alat}

Bahan yang digunakan pada penelitian ini adalah bibit merawan (Hopea odorata Roxb.) asal sistem KOFFCO berumur enam bulan yang ditumbuhkan di polibag, potray kotak dan potray bulat. Peralatan yang digunakan antara lain adalah alat ukur parameter pertumbuhan bibit, alat tulis, oven, peralatan untuk membongkar bibit dan seperangkat komputer yang dilengkapi software SPSS 12 untuk analisis data.

\section{Pengumpulan Data dan Penilaian Mutu Bibit}

Penilaian mutu fisik bibit dilakukan setelah bibit berumur enam bulan yang ditumbuhkan pada tiga wadah dengan volume media berbeda yaitu polibag (A) volume $500 \mathrm{~cm}^{3}$, potray kotak (B) volume $350 \mathrm{~cm}^{3}$ dan potray bulat (C) volume $300 \mathrm{~cm}^{3}$. Penilaiannya dilakukan secara sampling yaitu dengan mengambil sepuluh sampel bibit pada tiap macam wadah tersebut yang dipilih secara acak di persemaian (simple random sampling). Dengan demikian, total bibit yang dinilai adalah 30 bibit. Adapun tahapan penilaiannya adalah sebagai berikut :

1. Melakukan pengukuran tinggi dan diameter bibit, serta tinggi dan diameter tunas.

2. Melakukan pengukuran terhadap berat kering bagian/organ bibit yaitu : berat kering akar (BKA), berat kering pucuk/batang dan daun (BKP) dan berat kering total bibit (BKT). Berat kering diperoleh dengan mengoven organ bibit pada suhu $105^{\circ} \mathrm{C}$ sampai beratnya konstan (sekitar 24 jam).

3. Hasil pengukuran pada tahap sebelumnya digunakan untuk mengkuantifikasi parameter mutu fisik bibit yaitu kekokohan, rasio pucuk akar (RPA) dan indeks mutu bibit (IMB). Formula yang digunakan adalah sebagai berikut :
a. Kekokohan $=\frac{\text { Tinggi }(\mathrm{cm})}{\text { Diameter }(\mathrm{mm})}$
(Hendromono, 2003)
b. $\mathrm{RPA}=\frac{\mathrm{BKA}(\mathrm{g})}{\text { Berat kering pucuk }(\mathrm{g})}$ (Hendromono, 2003)
c. IMB $=\frac{\text { BKT }(\mathrm{g})}{\text { RPA }+ \text { Kekokohan }}$ (Dickson et al. ,1960 dalam Hendromono, 2003) 
4. Bibit dinilai siap tanam apabila memenuhi kriteria berikut ini :

a. Tinggi bibit lebih dari $20 \mathrm{~cm}$ (Riyantoko, 1999 dalam Srihadiono, 2005)

b. Nilai RPA ada pada kisaran 2-5 (Alrasyid, 1972 dalam Mindawati \& Yusnita, 2005)

c. Nilai IMB $\geq 0,09$ (Lackey \& Alm, 1982 dalam Hendromono, 2003)

d. Bibit dengan kekokohan lebih tinggi cenderung lebih layak untuk ditanam.

Pengamatan kandungan hara media bibit dilakukan untuk mengetahui kesuburan media yang digunakan. Variabel yang dianalisis adalah kandungan $\mathrm{C}$ dan $\mathrm{N}$ total yang dianalisa dengan metode Kjeldahl; serta kandungan $\mathrm{P}_{2} \mathrm{O}_{5}$ yang dianalisis dengan metode penjenuhan Amonium Acetat $\mathrm{pH} 7$.

\section{Analisis Data}

Analisis statistik dilakukan untuk mengetahui tingkat validitas (kepercayaan) dari hasil penilaian mutu bibit yang dilakukan. Analisis pengaruh umur bibit terhadap kualitas bibit dilakukan melalui uji $\mathrm{F}$ (one way ANOVA) dan uji lanjut Duncan dengan model ANOVA $\mathrm{Y}_{\mathrm{ij}}=\mu+\mathrm{A}_{\mathrm{i}}+\mathrm{E}_{\mathrm{ij}}$, dengan $\mathrm{Y}_{\mathrm{ij}}=$ Parameter pertumbuhan dan mutu fisik bibit pada umur bibit ke-i dan ulangan ke- $\mathrm{j} ; \mu=$ rata-rata populasi; $\mathrm{A}_{\mathrm{i}}=$ pengaruh umur bibit ke-i dan $\mathrm{E}_{\mathrm{ij}}=$ Error pengaruh umur bibit ke-i dan ulangan ke-j. Analisis kelayakan bibit siap tanam dilakukan melalui uji-t satu sampel (one sample $t$-test) yaitu dengan membandingkan nilai tinggi bibit dengan nilai 20, RPA bibit dengan nilai RPA standar (2 atau 5) dan nilai IMB bibit dengan nilai IMB standar $(0,09)$.

\section{HASIL DAN PEMBAHASAN}

\section{A. Pertumbuhan Bibit}

Hasil uji F menunjukkan bahwa tinggi bibit dan tunas merawan asal sistem KOFFCO umur 6 bulan tidak dipengaruhi secara nyata $(p>0,05)$ oleh wadah bibit. Akan tetapi secara deskriptif tampak bahwa tinggi bibit dan tunas di polibag (A) cenderung lebih tinggi dibandingkan dengan bibit di potray kotak (B) dan bulat (C). Pada umur 6 bulan tinggi bibit dan tunas A adalah 21,59 $\mathrm{cm}$ dan 15,16 cm; sedangkan B adalah 17,5 cm dan 12,57 cm serta $C$ adalah 16,6 cm dan 11,54 cm (Gambar 1).

Hasil uji F menunjukkan bahwa diameter bibit tidak dipengaruhi secara nyata $(p>0,05)$ oleh wadah bibit. Akan tetapi diameter tunas dipengaruhi secara nyata $(p<0,05)$ oleh wadah bibit. Selanjutnya, hasil uji lanjut Duncan menunjukkan bahwa diameter tunas bibit A secara nyata $(\mathrm{p}<$ $0,05)$ lebih besar dibandingkan $\mathrm{B}$, tetapi tidak berbeda nyata $(\mathrm{p}>0,05)$ dengan bibit $\mathrm{C}$. Adapun diameter tunas pada masing-masing bibit adalah A 3,00 mm; B 2,50 mm dan C 2,61 mm (Gambar 2).

Hasil Uji F terhadap berat kering komponen bibit yakni berat kering akar (BKA), bagian bibit di atas permukaan tanah/berat kering pucuk (BKP) dan berat kering total bibit (BKT) menunjukkan bahwa semua berat kering komponen bibit tidak dipengaruhi secara nyata $(p>0,05)$ oleh wadah bibit. Akan tetapi secara deskriptif tampak bahwa berat kering komponen bibit di polibag (A) cenderung 
lebih berat dibandingkan bibit di potray (B dan C). Hal ini mengindikasikan bahwa pertumbuhan bibit di polibag cenderung lebih baik dibandingkan di potray.

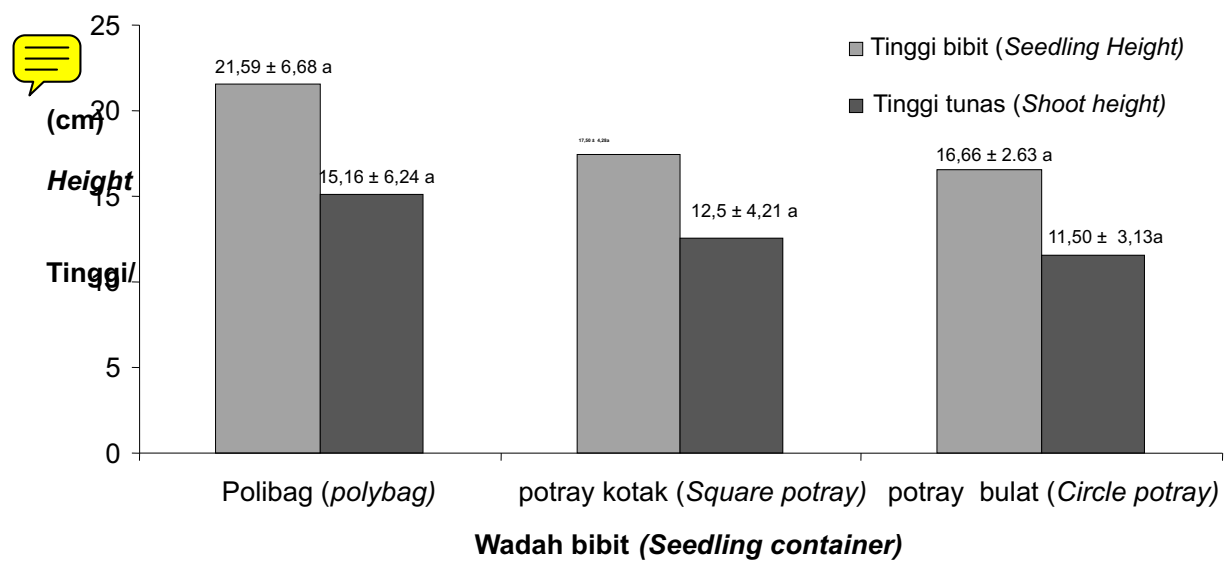

Gambar (Figure) 1. Tinggi bibit dan tunas bibit merawan pada umur enam bulan di polibag dan potray.

(Seedling and seedling shoot height of Hopea odorata at six months old on polybag and potrays)

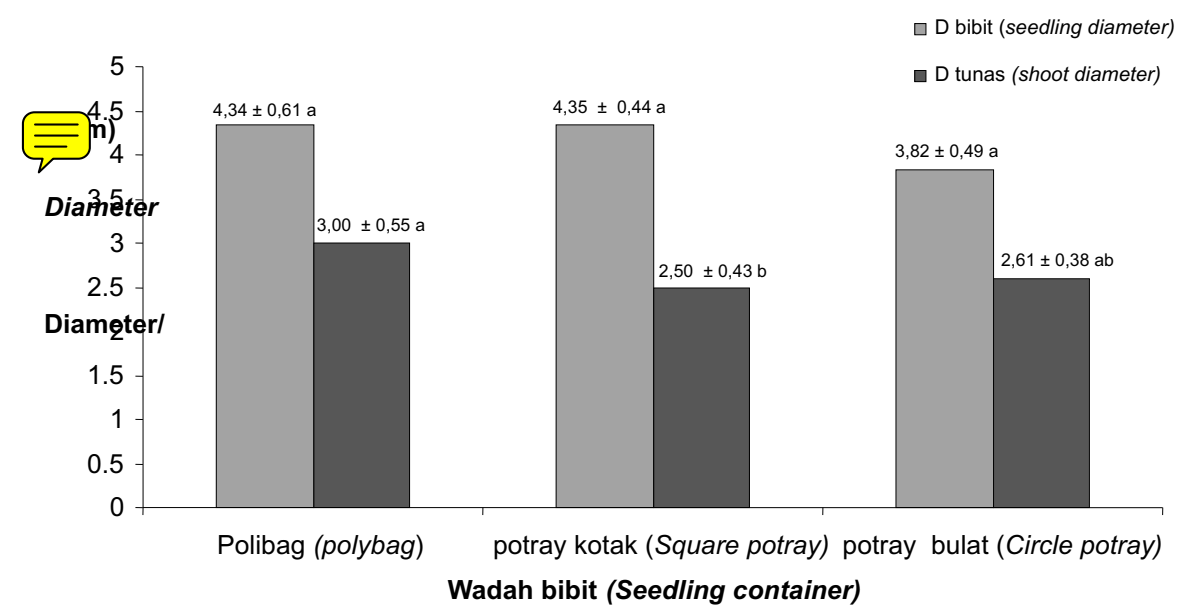

Gambar (Figure) 2. Diameter bibit dan tunas merawan pada umur enam bulan di ploybag dan potray.

(Seedling and shoot of Hopea odorata diameters at six months on polybag and potrays)

Tabel (Table) 1. Berat kering bibit merawan pada umur enam bulan di polybag dan potray

(Dry matter of Hopea odorata seedlings at six months on polybag and potrays)

\begin{tabular}{|l|c|c|c|}
\hline Wadah bibit (Container type) & $\begin{array}{c}\text { BKA (DMR) } \\
(\mathrm{gr})\end{array}$ & $\begin{array}{c}\text { BKP (DMSh) } \\
(\mathrm{gr})\end{array}$ & $\begin{array}{c}\text { BKT (DMSe) } \\
(\mathrm{gr})\end{array}$ \\
\hline Polybag/Polybag & $1,05 \pm 0,6 \mathrm{a}$ & $2,01 \pm 1,03 \mathrm{~A}$ & $3,06 \pm 1,63 \mathrm{a}$ \\
\hline Potray kotak/Square potray & $0,68 \pm 0,33 \mathrm{a}$ & $1,51 \pm 0,52 \mathrm{~A}$ & $2,20 \pm 0,76 \mathrm{a}$ \\
\hline Potray bulat/Circle potray & $0,71 \pm 0,15 \mathrm{a}$ & $1,84 \pm 0,36 \mathrm{~A}$ & $2,56 \pm 0,40 \mathrm{a}$ \\
\hline
\end{tabular}

Keterangan (Remarks) : angka yang diikuti huruf yang berbeda dalam satu kolom berbeda nyata berdasarkan uji Duncan taraf 5\% (The numbers was followed by different letters are significantly different at 5\% level with Duncan test $)$; BKA $/ D M R=$ berat kering akar (dry matter of root); $\mathrm{BKP}=$ berat kering pucuk/DMSh (dry matter of shoot); BKT = berat kering total/DMSe (dry matter of seedling) 
Hasil perhitungan perbedaan besaran parameter pertumbuhan bibit antara bibit di polibag (A) dan di potray (B dan C) menunjukkan bahwa perbedaan pertumbuhan terkecil diperoleh pada pertumbuhan diameter bibit yaitu 6\% dan terbesar pada pertumbuhan berat kering akar (BKA) yaitu 51\% (Tabel 2). Sementara itu, berat kering total (BKT) yang merupakan representasi dari pertumbuhan total bibit, berbeda 29\% antar bibit. Dengan demikian karena BKT merupakan representasi dari pertumbuhan total bibit maka hasil tersebut menunjukkan bahwa pertumbuhan A 0,29 kali lebih cepat dibandingkan B dan C.

Wadah bibit dengan kapasitas/volume yang berbeda akan menyebabkan perbedaan kuantitas media yang digunakan. Sementara itu, kualitas media yang digunakan tidak berbeda karena menggunakan jenis media yang sama yaitu campuran top soil dengan sekam padi $(1: 1 \mathrm{v} / \mathrm{v})$. Media berperan seperti halnya tanah di lapangan yakni berfungsi sebagai ruang tempat tumbuh akar serta menyediakan air dan nutrisi bagi tanaman/bibit. Dengan demikian maka kuantitas media yang berbeda akan menyebabkan perbedaan kuantitas ruang tumbuh, air dan nutrisi bagi pertumbuhan bibit. Ruang tumbuh akar, air dan nutrisi pada bibit $\mathrm{A}$ (volume media $=500 \mathrm{~cm}^{3}$ ) akan lebih besar dibandingkan bibit $\mathrm{B}$ (volume media $=400 \mathrm{~cm}^{3}$ ) dan $\mathrm{C}\left(\right.$ volume media $\left.=350 \mathrm{~cm}^{3}\right)$. Dengan penjelasan ini, dapat dipahami apabila pertumbuhan bibit (tinggi, diameter dan berat kering) A lebih baik dibandingkan B dan C.

Tabel (Table) 2. Perbedaan besaran pertumbuhan antara bibit merawan di wadah polibag dengan potray (Hopea odorata seedling growth difference between its container in polybag and potrays)

\begin{tabular}{|l|c|c|}
\hline $\begin{array}{c}\text { Parameter pertumbuhan bibit } \\
\text { (Growth parameters of seedling) }\end{array}$ & $\begin{array}{c}\text { Besar perbedaan } \\
\text { (Magnitude of difference) }\end{array}$ & $\begin{array}{c}\text { Persentase perbedaan (\%) } \\
\text { (percentage of difference) }\end{array}$ \\
\hline Tinggi bibit (Seedling height) $(\mathrm{cm})$ & 3,81 & 26 \\
\hline Tinggi tunas (Shoot height) & 2,58 & 6 \\
\hline Diameter bibit (seedling diameter) $(\mathrm{mm})$ & 1,23 & 26.3 \\
\hline Diameter pucuk (Shoot diameter) $(\mathrm{mm})$ & 0,19 & 25 \\
\hline Berat kering pucuk (dry matter of shoot) $(\mathrm{gr})$ & 0,42 & 51 \\
\hline Berat kering akar (dry matter of root) $(\mathrm{gr})$ & 0,41 & 29 \\
\hline Berat kering total (dry matter of seedling) $(\mathrm{gr})$ & & \\
\hline
\end{tabular}

Pertumbuhan bibit merawan asal sistem KOFFCO yang diberi aplikasi arang kompos nilam $200 \mathrm{~g}$ dilaporkan oleh Frianto (2008). Hasil penelitiannya menunjukkan tinggi dan diameter tunas bibit umur 3 bulan adalah 24,9 $\mathrm{cm}$ dan 2,69 $\mathrm{mm}$. Hasil tersebut lebih baik dibandingkan yang diperoleh dari penelitian ini (pada umur 6 bulan tinggi tunas 14,3 cm dan diameter tunas 2,94 mm). Pertumbuhan yang lebih baik ini dicapai karena kandungan hara media yang digunakan yakni arang kompos nilam lebih baik daripada kandungan hara media bibit pada penelitian ini (Tabel 3). Dibandingkan dengan 
media campuran top soil dengan sekam padi yang digunakan sebagai media bibit pada penelitian ini. Media pembibitan pada penelitian terdiri dari campuran top soil dengan sekam padi $(2: 1, \mathrm{v} / \mathrm{v})$.

Tabel (Table) 3. Perbandingan antara kandungan hara media yang digunakan dengan arang kompos nilam (Nutrion content comparison between media and patchouli charcoal-compost)

\begin{tabular}{|c|c|c|}
\hline $\begin{array}{c}\text { Kandungan hara } \\
\text { (Nutrition content) }\end{array}$ & $\begin{array}{c}\text { Media pembibitan } \\
\text { (Planting media) }\end{array}$ & $\begin{array}{c}\text { Arang kompos nilam } \\
\text { (Patchouli charcoal-compost) }\end{array}$ \\
\hline $\mathrm{C}(\%)$ & 4,65 & 20,4 \\
$\mathrm{~N}(\%)$ & 0,39 & 2,17 \\
$\mathrm{C} / \mathrm{N}$ & 11,9 & 9,4 \\
$\mathrm{P}_{2} \mathrm{O}_{5}(\%)$ & 0,1 & 1,5 \\
\hline
\end{tabular}

\section{B. Mutu Fisik Bibit}

Mutu bibit diartikan sebagai suatu ekspresi dari gambaran lebih jauh terhadap sebuah bibit yang diharapkan dapat beradaptasi dan tumbuh setelah penanaman (Wilson dan Jacobs, 2005 yang dikutip oleh Nurhasybi \& Sudrajat, 2006). Mutu bibit merupakan awal yang akan menentukan kualitas hutan yang akan dibangun dan tegakan yang ada di dalamnya (Balai Teknologi Perbenihan, 1998).

Hasil uji F menunjukkan bahwa semua parameter mutu fisik bibit tidak dipengaruhi secara nyata $(\mathrm{p}<0,05)$ oleh wadah bibit. Hal ini menunjukkan bahwa mutu fisik di antara bibit adalah seragam. Namun, ada kecenderungan bahwa kekokohan dan indeks mutu bibit (IMB) A lebih tinggi dibandingkan B dan C. Sementara itu, untuk nilai rasio pucuk akar (RPA) terjadi sebaliknya. Adapun nilai kekokohan, RPA dan IMB A umur enam bulan berturut-turut adalah 4,73, 2,06 dan 0,48 (Gambar 3).

Nilai parameter mutu fisik bibit ditentukan oleh besaran parameter pertumbuhannya. Kekokohan bibit ditentukan oleh rasio antara tinggi dengan diameter bibit, RPA bibit ditentukan oleh rasio antara BKP dengan BKA dan IMB ditentukan oleh rasio antara BKT dengan kekokohan ditambah RPA. Dengan demikian maka tidak berbeda nyatanya semua parameter mutu bibit menunjukkan dua hal yaitu : rasio pertumbuhan vertikal dengan horizontal antara bibit dengan wadah yang berbeda adalah sama, begitupun dengan perbandingan pertumbuhan organ bibit di atas permukaan (bagian pucuk) dengan pertumbuhan organ bibit di bawah permukaan (perakaran).

\section{Kelayakan Siap Tanam Bibit}

Idealnya untuk menilai kelayakan bibit siap tanam, secara utuh harus memperhitungkan mutu fisik, fisiologis dan genetik. Akan tetapi dalam praktiknya diperlukan metode yang tidak sederhana dan waktu yang tidak singkat. Padahal dalam menilai kelayakan siap tanam bibit, di antaranya harus menggunakan metode yang relatif sederhana dan dilakukan dengan cepat (Nurhasybi dan Sudrajat, 2006). Adapun cara yang dianggap relatif sederhana, cepat dan hasilnya masih dipercaya adalah berdasarkan penampilan fisik/morfologi bibit. Dengan pertimbangan tersebut untuk menilai 
kelayakan siap tanam bibit merawan didasarkan pada penampilan morfologinya yaitu tinggi tanaman, RPA dan IMB.
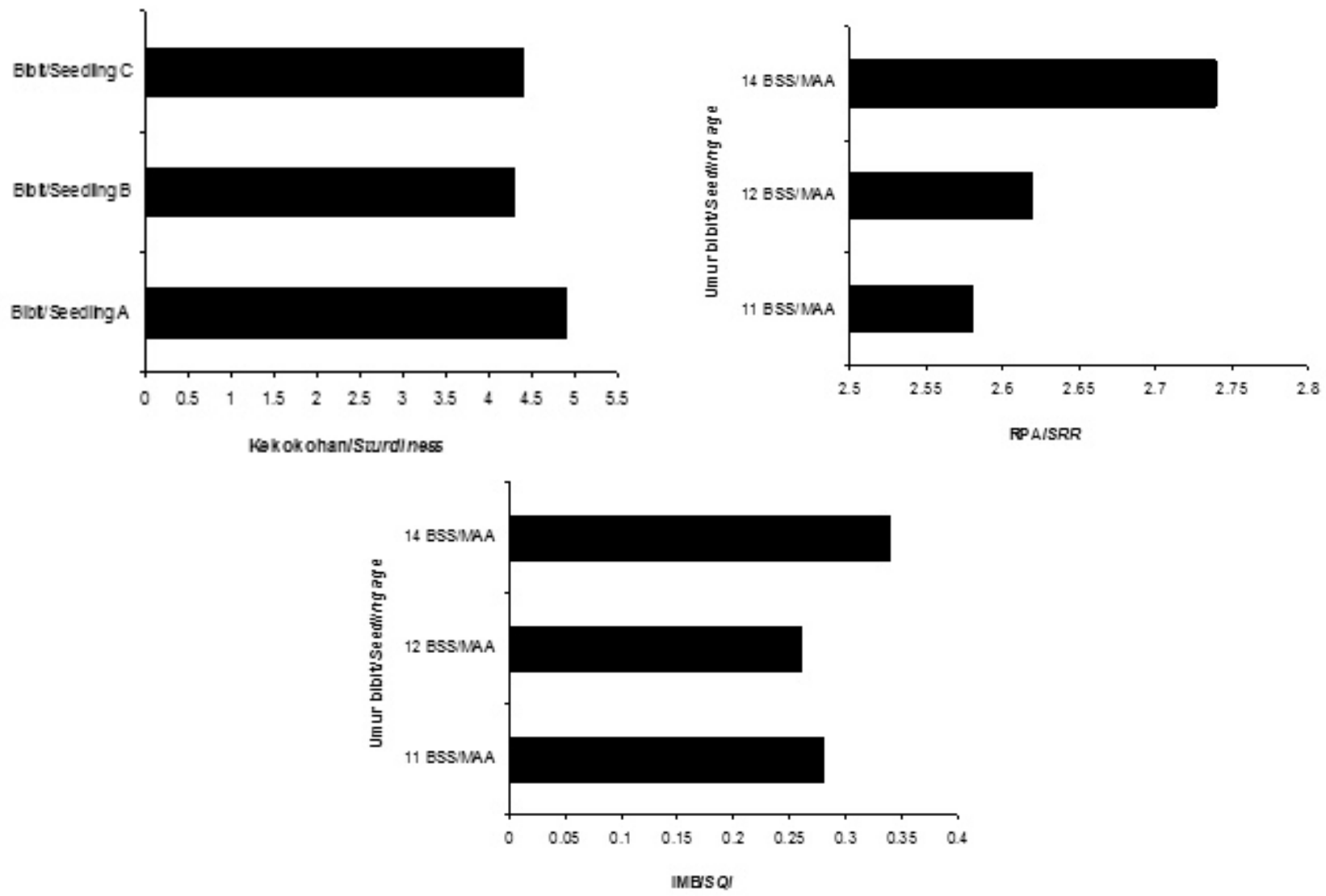

Keterangan (Remarks) : A = Polibag (polybag), $\mathrm{B}=$ potray kotak (square potray) \& $\mathrm{C}=$ potray bulat (circle potray); $\mathrm{RPA}=$ rasio pucuk akar (shoot-root ratio) IMB/SQI= indeks mutu bibit (seedling quality index)

Gambar (Figure) 3. Variasi kekokohan, RPA, dan IMB bibit Hopea odorata Roxb. pada tiga macam wadah (TheVariation of sturdiness, shoot/root ratio, and seedling quality index of Hopea odorata Roxb. at three kind containers)

Bedasarkan penampilan morfologinya, bibit merawan dikategorikan siap tanam jika memenuhi persyaratan tinggi bibit lebih dari $20 \mathrm{~cm}$ (Riyantoko,1999 yang dikutip oleh Srihadiono, 2005), RPA ada pada kisaran 2-5 (Alrasyid, 1972 yang dikutip oleh Mindawati dan Susilo, 2005) dan IMB di atas 0,09 (Lackey dan Alm, 1982 yang dikutip oleh Durahim dan Hendromono, 2006).

Hasil uji-t (one sample t-test) menunjukkan bahwa tinggi semua bibit belum secara nyata $(\mathrm{p}<0,05)$ lebih tinggi dari $20 \mathrm{~cm}$, tetapi IMB semua bibit secara nyata $(\mathrm{p}<0,05)$ sudah lebih besar dari 0,09 dan RPA-nya ada pada kisaran 2-5. Apabila memperhitungkan semua kriteria tersebut, tampak bahwa secara statistik sampai umur enam BST tidak ada satu pun bibit yang sudah layak tanam. Akan tetapi, secara angka (nilai) tampak bahwa bibit yang ditumbuhkan di polibag (A) sudah layak tanam 
karena tinggi rata-ratanya sudah lebih dari $20 \mathrm{~cm}$ yakni 20,3 cm, RPA ada pada kisaran 2-5 yakni 2,1 dan IMB lebih dari 0,09 yakni 0,46.

\section{KESIMPULAN}

1. Media dalam polibag dengan volume media $500 \mathrm{~cm}^{3}$ secara signifikan memberikan pertumbuhan lebih baik pada bibit merawan asal sistem KOFFCO umur enam bulan dibandingkan potray (potray kotak volume $350 \mathrm{~cm}^{3}$ dan potray bulat $300 \mathrm{~cm}^{3}$ ).

2. Untuk mencapai kriteria siap tanam, bibit merawan asal sistem KOFFCO dalam potray membutuhkan waktu yang lebih lama dibandingkan bibit dalam polibag.

\section{DAFTAR PUSTAKA}

Balai Teknologi Perbenihan. 1998. Program nasional sistem perbenihan kehutanan. Publikasi Khusus. Balai Teknologi Perbenihan. Bogor.

Hendromono. 2003. Kriteria peniliaian mutu bibit dalam wadah yang siap tanam untuk rehabilitasi hutan dan lahan. Buletin Penelitian dan Pengembangan Kehutanan 4(1) : 11-20. Badan Litbang Kehutanan. Jakarta.

Hidayat, A., H. Hendalastuti \& E. Nurrohman. 2007. Pengaruh ukuran diameter stek batang Hopea odorata Roxb. dari kebun pangkas terhadap kemampuan bertunas, berakar dan daya hidupnya. Jornal Penelitian Hutan dan Konservasi Alam 4 (1) : 1 - 12. Pusat Penelitian dan Pengembangan Hutan dan Konservasi Alam. Bogor.

Mindawati, N \& S. Yusnita. 2005. Pengaruh macam media terhadap pertumbuhan semai Acacia mangium Willd. Jurnal Penelitian Hutan dan Konservasi Alam 2(1) : 53-59. Pusat Peneltian dan Pengembangan Hutan dan Konservasi Alam. Bogor. Soerinegara, I dan R.H.M.J. Lemmens. 1994. Plant resources of South-East Asia. Timber trees, Major commercial timbers. Prosea. Bogor.

Nurhasybi \& P.J Sudradjat. 2006. Bagaimana mutu bibit tanaman hutan yang ideal? Tinjauan singkat untuk pengadaan bibit bermutu. Prosiding seminar hasil-hasil penelitian Balai Litbang Teknologi Perbenihan di Bogor Tanggal 14 Pebruari 2006. Hlm 179 -183. Pusat Penelitian dan Pengembangan Hutan Tanaman. Bogor.

Sakai, C. \& A. Subiakto. 2007. Pedoman pembuatan stek jenis-jenis dipterokarpa dengan KOFFCO sistem. Pusat Penelitian dan Pengembangan Hutan dan Konservasi Alam. Bogor.

Schmidth, F.H \& J.H.A. Ferguson. 1951. Rainfall typed based on wet and dry period ratios for Indonesia with western New Guinea. Verhand N0. 42. Direktorat Meteorologi \& Geofísika. Jakarta. 
Soerinegara, I \& R.H.M.J. Lemmens. 1994. Plant resources of South East Asia timber trees. Major comercial timers. Prosea. Bogor.

Srihadiono, U.S. 2005. HTI : Skenario masa depan kehutanan Indonesia. PT. Musi Hutan Persada \& Wana Aksara. Palembang.

Weinland, G. 1998. Review of Dipterocarps : Taxonomy, Ecology and Silviculture. CIFOR. Bogor. 